\title{
Simbolisme Bromance di Media Sosial
}

\section{Bromance Simbolism in Social Media}

\author{
Pandu Bagus Pratama', Sumekar Tanjung ${ }^{2}$ \\ 1,2Program Studi Ilmu Komunikasi, Universitas Islam Indonesia, Sleman \\ Yogyakarta, Indonesia
}

\section{Author's email: \\ ${ }^{1}$ Email: \\ 17321040@students.uii.ac.id \\ ${ }^{2}$ Email: \\ sumekar.tanjung@uii.ac.id}

\begin{abstract}
:
Bromance is the concept of friendly interactions between men who like each other and even love each other, but have limitations in sexual orientation. This study aims to present an analysis of the Bromance representation between Raditya Dika and Pandu Winoto. The data to be analyzed sourced from the video on Raditya Dika's YouTube Channel. This study uses qualitative methods and Roland Barthes' semiotic analysis techniques. The result of this research is that the researcher found three categories of representation of Bromance in the video, namely in terms of dialogue, action, and appearance. Researchers hope that this research can add insight and literacy in the community, especially Indonesia related to Bromance.
\end{abstract}

Keywords: Bromance, Semiotics, YouTube, Representation, Signs

\begin{abstract}
Abstrak:
Bromance merupakan konsep interaksi persahabatan antar laki-laki yang saling menyukai bahkan menyayangi satu sama lain, namun memiliki batasan dalam orientasi seksual. Penelitian ini bertujuan memaparkan analisis mengenai representasi Bromance antara Raditya Dika dan Pandu Winoto. Data yang akan dianalisis berasal dari video pada Channel YouTube Raditya Dika. Penelitian ini menggunakan metode kualitatif dan teknik analisis semiotika Roland Barthes. Hasil penelitian ini adalah peneliti menemukan tiga kategori representasi Bromance dalam video yakni dari segi dialog, tindakan, dan penampilan. Peneliti berharap penelitian ini dapat menambah wawasan maupun literasi masyarakat khususnya Indonesia terkait dengan Bromance.
\end{abstract}

Kata kunci: Bromance, Semiotika, YouTube, Representasi, Tanda 


\section{PENDAHULUAN}

Dengan media sosial, seseorang dapat saling berinterkasi tanpa mengenal jarak dan waktu. Aktivitas yang dilakukan pengguna media sosial bervariasi, mulai dari membagikan pengalaman, informasi, berkomunikasi, hingga mempublikasikan kehidupan sehari-hari. Aktivitas tersebut dimuat dalam berbagai platform seperti Instagram, Whatsapp, Twitter, Facebook serta YouTube.

YouTube menjadi salah satu media sosial yang digemari. Output YouTube berupa audio visual. Ini menjadikan konten yang disajikan di dalamnya menarik. Seringkali, YouTube digunakan sebagai media untuk menyalurkan atau memublikasikan kreativitas seseorang di berbagai bidang, bahkan terdapat pula konten mengenai kehidupan seseorang atau sering disebut dengan vlog. Namun, pembuat konten (content creator) mengemas dengan cara yang berbeda, misalnya dengan menampilkan peristiwa-peristiwa unik dalam kehidupannya atau berbagi pengalaman pribadi yang membuat pemirsa merasa terhibur.

Terdapat sejumlah content creator di Indonesia yang memiliki berbagai konten menghibur sehingga dapat menarik penonton. Salah satunya ialah Raditya Dika. Radit, begitu biasa disapa, telah memiliki channel milik pribadi di YouTube sejak 28 Juni 2007. Kini, video yang diunggah telah mencapai lebih dari 1000 dan channel tersebut sempat berada di posisi teratas dilihat dari jumlah subscribers. Untuk saat ini, jumlah subscibers pada channel Raditya Dika telah mencapai lebih dari 9 juta (Noxinfluencer, 2020).

Salah satu konten YouTube Radit adalah persahabatan antara Radit dengan Pandu. Ini telah menarik jutaan orang. Radit sering mengajak Pandu untuk mencoba makanan, berekreasi, hingga me-review produk. Hubungan persahabatan antar laki-laki disebut juga dengan Bromance. Istilah memperlihatkan kekuatan hubungan emosional secara intens dimiliki oleh laki-laki heteroseksual (DeAngelis, 2014).
Hubungan persahabatan antar laki-laki yang sudah akrab menjadi menarik untuk diteliti. Fokus penelitian ini, yaitu bagaimana suatu tayangan dapat merepresentasikan bromance Raditya Dika dan Pandu Winoto yang terdapat pada Channel YouTube Raditya Dika. Peneliti memilih objek tersebut karena memiliki jumlah subscibers yang tinggi. Selain itu, Raditya Dika merupakan public figure yang terkenal dengan karya-karya yang telah digemari masyarakat Indonesia mulai dari film, buku hingga konten- konten pada akun media sosial. Namun, peneliti akan melihat dengan sudut pandang yang berbeda, yaitu dari segi hubungan persahabatan antara Raditya Dika dan Pandu Winoto yang ditampilkan dalam video-video di channel Raditya Dika. Ini masih jarang terjadi dalam masyarakat Indonesia sehingga peneliti memilih tema tersebut agar konsep tentang bromance dipahami dengan tepat melalui pemilihan objek yang telah dikenal oleh masyarakat Indonesia.

Untuk memperkaya penelitian, analisis akan melihat bagaimana representasi bromance Raditya Dika dan Pandu Winoto dalam channel YouTube Raditya Dika. Tujuan dalam penelitian ini yaitu memaparkan analisis mengenai Bromance Raditya Dika dan Pandu Winoto dalam channel YouTube Raditya Dika.

\section{KERANGKA TEORI}

Menurut Hanani \& Reza (2019), bromance merupakan ikatan emosional yang positif sehingga dalam hubungan tersebut terdapat perasaan saling pengertian dan dukungan. Keakraban yang berlangsung pada suatu hubungan antarindividu seperti persahabatan dan dapat menghasilkan respon positif, misalnya, orang-orang yang memiliki perasaan suka satu sama lain dapat saling membantu dan memahami, mempunyai kesamaan bidang tertentu mengenai kegiatan dan minat, menghargai dan suka atas kehadiran satu sama lain, sikap dan perasaan saling mempercayai, sehingga dapat menimbulkan 
rasa nyaman serta saling menyediakan dukungan emosional.

Utomo (2017) menjelaskan bahwa media baru merupakan berbagai perangkat teknologi komunikasi dengan berbagai ciri yang sama, selain baru dimungkinkan adanya digitalisasi serta ketersediaannya luas sebagai alat komunikasi untuk penggunaan pribadi. Media baru memiliki ciri utama, yakni adanya saling keterhubungan dengan berbagai kemudahan yang diberikan seperti dapat diakses dimanapun, khalayak individu sebagai pengirim atau penerima pesan, interaktivitasnya, serta memiliki keberagaman kegunaan juga sebagai karakter yang terbuka.

Kehadiran media sosial berdampak besar di bidang komunikasi. Media sosial mengubah cara masyarakat berkomunikasi dalam kehidupan sehari- hari disegala bidang. Selain itu, terdapat perubahan menjadi komunikasi yang serba digital dan berlangsung dengan mudah secara cepat serta efektif (Clara Sari et al., 2018).

\section{METODE PENELITIAN}

Penelitian ini menggunakan pendekatan kualitatif. Pada penelitian ini, hal yang akan dianalisis terkait dengan tanda-tanda dari representasi bromance dalam video yang diunggah pada YouTube Raditya Dika. Fokus objek penelitian, yaitu video Raditya Dika dan Pandu Winoto yang termuat dalam channel YouTube milik Raditya Dika. Dalam video, terdapat beberapa tanda yang berbentuk teks dan gambar yang merepresentasikan bromance. Peneliti menggunakan metode Semiotika Roland Barthes. Semiotika Roland Barthes memiliki dua tingkatan sistem bahasa. Tingkat pertama sistem tanda disebut denotasi yang mana bahasa berposisi sebagai objek dan pada tingkat kedua sistem tanda disebut konotasi yang mana sistem bahasa sebagai meta bahasa. Bahasa adalah sistem tanda yang memiliki dua unsur utama didalamnya yaitu penanda (signifier) dan petanda (signified).
Dalam melakukan analisis secara semiotik, Roland Barthes menam-bahkan mitos untuk menggali lebih dalam makna suatu teks. Konsep mitos berada pada pemaknaan tataran sistem bahasa yang kedua. Barthes mengemukakan bahwa mitos merupakan pengembangan dari konotasi yang telah terbentuk sejak lama oleh masyarakat. Mitos juga dapat dikatakan produk kelas sosial yang telah memiliki dominasi. Dalam semiotika, mitos bukan tentang sesuatu yang tahayul atau tidak masuk akal, melainkan type of speech (gaya bicara) yang dimiliki seseorang (Vera, 2014).

Objek penelitian adalah konten video yang terunggah dalam channel YouTube milik Raditya Dika ketika Raditya Dika bersama Pandu Winoto yang dijadikan objek teks serta visual atau dengan menggunakan dialog dalam bentuk audio. Dari pengamatan tersebut, peneliti menentukan 10 scene dalam video untuk dianalisis sesuai dengan fokus penelitian.

Tahapan - tahapan dalam melakukan analisis, yaitu menjelaskan tentang fokus objek penelitian yang akan dianalisis.

1. Mengumpulkan data dalam betuk sampel gambar pada video yang dapat mewakili dan dianggap sesuai fokus penelitian.

2. Melakukan analisis denotatif dalam memaknai suatu tanda tertentu, yang dilanjutkan analisis konotatif dalam memaknai suatu pesan yang tersirat.

3. Menarik kesimpulan, yaitu representasi simbolisme bromance Raditya Dika dan Pandu Winoto yang termuat dalam channel YouTube milik Raditya Dika.

\section{HASIL DAN PEMBAHASAN}

Pada bagian ini, akan dianalisis makna dari scene yang diambil untuk penelitian ini. Scene yang diambil meliputi di antaranya percakapan, tindakan, dan penampilan. 


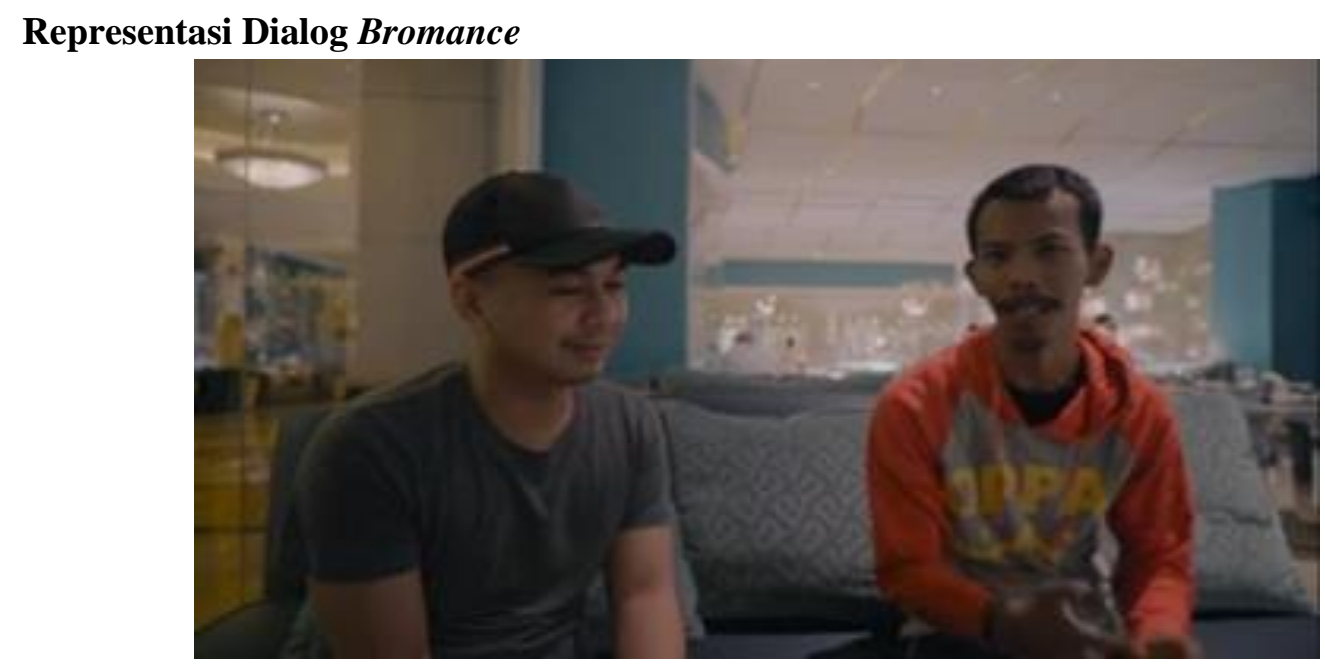

Gambar 1. Pandu Winoto sedang mentraktir makan Raditya Dika

Tabel 1. Tanda Dialog Bromance

\begin{tabular}{c}
\hline Tanda (sign) \\
\hline "Minta maap bang" \\
"Dia minta maaf, terus mau traktir makan gue di hotel \\
mulia, karena dia tau, gue suka banget makan disini, \\
terus dia bilang yaudah deh gua traktir makan elu bang \\
di hotel Mulia, makasih ya ndu ya"
\end{tabular}

Pada gambar $1(00.55-01.16)$, teknik pengambilan gambar menggunakan medium shot yang dapat menampilkan gambar setengah badan dari objek. Terlihat Raditya Dika di sebelah kiri dan Pandu Winoto di sebelah kanan dalam satu sofa panjang.

Ketika sedang berdialog, terlihat juga Pandu Winoto meminta maaf ke-pada Raditya Dika dengan mengatakan "Minta Maap Bang". Selain dengan ung-kapan tersebut, juga terdapat gesture yaitu sambil menyatukan kedua tangannya seperti sedang melalukan sungkem.

Tanda yang pertama diper-lihatkan melalui gesture Pandu Winoto yang menyatukan kedua tangan seperti sedang melakukan sungkem ke arah Raditya Dika sambil mengatakan "Minta maap ya bang".
Tindakan tersebut menggambarkan Pandu Winoto sedang benar-benar meminta maaf kepada Raditya Dika atas kesalahannya. Ekspresi wajah Pandu Winoto yang menunjukkan bahwa meminta maaf dengan serius atas kesalahannya yang diperbuat.

Respon Raditya Dika menunjukan bahwa menerima permintaan maaf tersebut dengan tulus ketika mengatakan "Dia minta maaf, terus mau traktir makan gue di hotel mulia karena dia tau gue suka banget makan di sini, terus dia bilang yaudah deh gua traktir makan elu bang di hotel Mulia, makasih ya Ndu ya". Dari dialog tersebut, Pandu Winoto serius meminta maaf kepada sahabatnya dengan mengajak ke tempat yang spesial. 


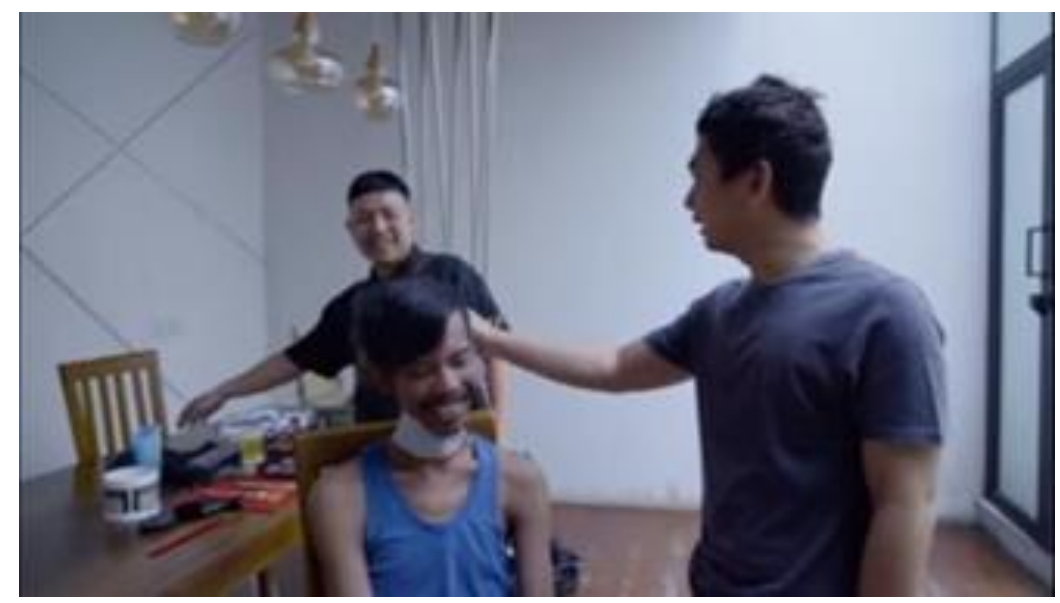

Gambar 2. Raditya Dika mengajak Pandu Winoto untuk memotong rambut

Tabel 2. Tanda Dialog Bromance

$\frac{\text { Tanda (sign) }}{\text { "I love Radit, bisa ngga..." }}$

Pada satu scene 2 (03.04-03.11), akan fokus mengenai dialog atau kata-kata yang dilontarkan. Peneliti menemukan bagian yang akan diteliti karena memiliki kesesuaian dengan fokus penelitian. Scene tersebut memperlihatkan seseorang yang hendak memotong rambut Pandu Winoto.

Ungkapan Pandu ketika mengatakan "I love Radit, bisa ngga..." dengan disaksikan secara langsung di depan Raditya Dika, meskipun dalam konteks bercanda. Ungkapan "I love..." kemudian dilanjutkan dengan nama seseorang, biasanya digunakan ketika seseorang mengungkapan perasaan cinta dan sayang kepada orang tersebut atau pasangannya. Namun, ketika hal tersebut terjadi pada hubungan persahabatan antar lakilaki seperti Raditya Dika dan Pandu Winoto, maka memiliki makna yang tersendiri. Secara tidak langsung, adegan ini hendak mengungkapkan bahwa Pandu Winoto memiliki ikatan erat dalam persahabatan dengan Raditya Dika sehingga meminta gaya rambut nantinya dengan bertuliskan "I love Radit".

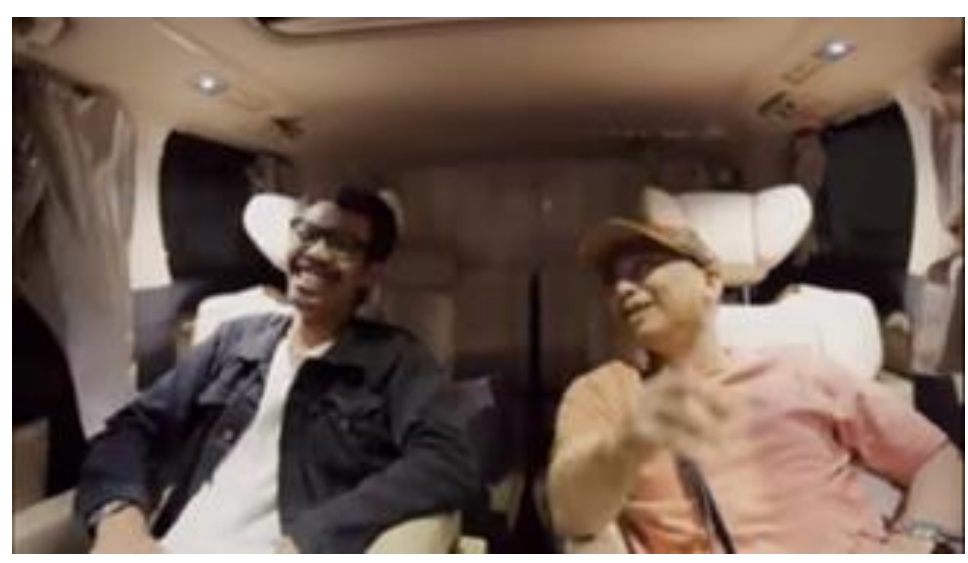


Gambar 3. Raditya Dika dan Pandu Winoto sedang duduk di dalam mobil

Tabel 3. Tanda Dialog Bromance

\section{Tanda (sign)}

"Sekarang gue sama istri kedua"

Pada scene 3 (00.06 - 00.18), pengambilan gambar menggunakan teknik medium shot karena berada di ruang yang sempit yaitu mobil. Terlihat Raditya Dika dan Pandu Winoto sedang berada di mobil, dan karena mereka berada di tengah mobil sehingga pengambilan gambar dilakukan dari sudut jok depan.

Tanda dalam dialog yang berhubungan dengan penelitian ini, yaitu ketika Raditya Dika sedang melakukan opening pada konten dan mengatakan "Sekarang gue sama istri kedua". Kalimat yang dikatakan oleh Raditya Dika dalam konteks sebelumnya pergi dengan anak dan istrinya. Ketika Raditya Dika mengatakan "Sekarang gue sama istri kedua" juga disertai dengan gesture tangan menunjuk ke arah Pandu Winoto.
Tanda lain yang menunjukkan bromance antara Raditya Dika dan Pandu Winoto, yakni dari segi dialog. Pada bagian pembukaan video, Raditya Dika mengawali dengan mengatakan "Sekarang gue sama istri kedua". Anggapan bahwa istri merupakan sosok perempuan sebagai teman hidup seorang suami dengan status menikah, tapi dalam scene tersebut memperlihatkan Raditya Dika hanya sedang bersama sahabat laki-lakinya yakni Pandu Winoto. Terdapat juga gesture yang mempertegas ketika Raditya Dika menganggap bahwa Pandu Winoto sebagai istri kedua, yaitu dengan menunjuk ke arahnya dan mengatakan "Pandu Winoto". Meskipun dalam konteks untuk kepentingan humor, Raditya Dika secara tidak langsung menyatakan bahwa Pandu Winoto adalah sahabat laki-lakinya

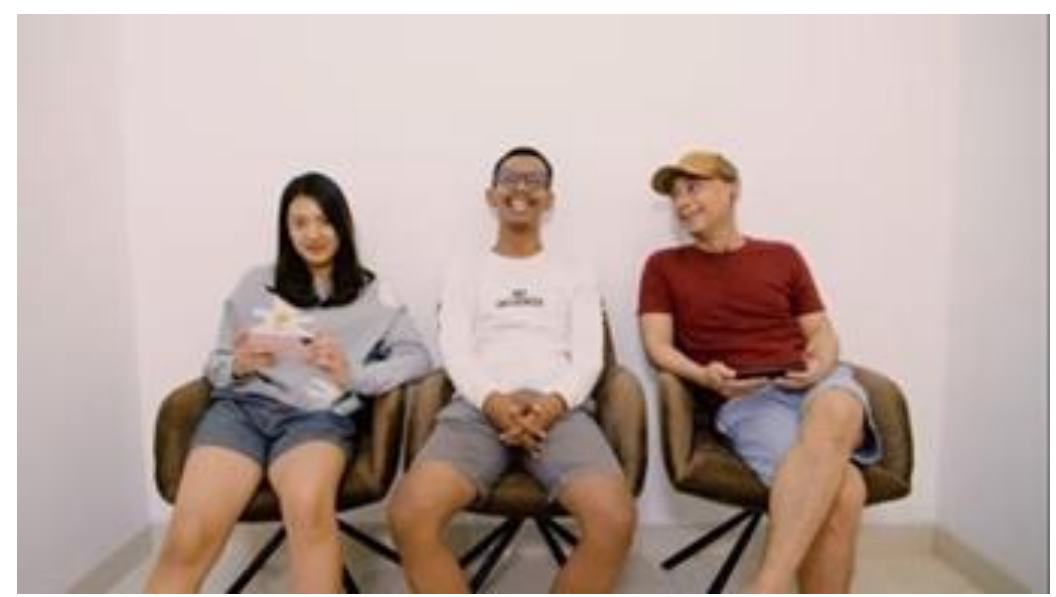

Gambar 4. Annisa Azizza, Pandu Winoto, dan Raditya Dika sedang duduk bersama

Tabel 4. Tanda Dialog Bromance

\begin{tabular}{c}
\hline Tanda (sign) \\
\hline "Halo semuanya di tengah tengah gua ada \\
kedua istri gua"
\end{tabular}


Pada scene 4 (00.01 - 00.09) pengambilan gambar menggunakan teknik medium shot. Namun, terlihat menggunakan lensa yang lebar karena dapat mengambil keseluruhan objek dan menyisakan sedikit ruang kosong di bagian samping. Ruangan tersebut terlihat tidak memiliki dekorasi apapun kecuali tiga kursi yang memang digunakan untuk duduk. Seperti biasa, Raditya Dika menyapa pemirsa sebagai pembuka. Namun, karena kali ini Raditya Dika bersama dua orang lainnya sehingga kalimat pembuka menjadi sedikit berbeda, yaitu "Halo semuanya di tengah tengah gua, ada kedua istri gua".

Di sisi lain, terlihat pada posisi duduk ketiga orang dalam scene tersebut yaitu Raditya Dika tetap berdampingan dengan Pandu Winoto meskipun telah mengajak Anissa Aziza. Ini menunjukan bahwa terdapat hubungan persahabatan yang erat antara Raditya Dika dan Pandu Winoto. Ada juga perkataan yang dilontarkan oleh Raditya Dika pada sesi pembuka yakni "Halo semuanya di tengah tengah gua ada kedua istri gua".

Kata "istri" yang menunjukkan hubungan sehidup semati akan lebih tepat ketika Raditya Dika menyakatakn hal tersebut hanya kepada Anissa Aziza, tapi dalam konteks ini juga menunjuk pada Pandu Winoto.

Tindakan Raditya Dika secara verbal maupun non verbal yang menunjukkan kedekatan hubungan persahabatan sesama laki-laki (bromance), terlihat mendapat tanggapan yang baik dari Pandu Winoto dan tidak ada unsur penolakan. Hal tersebut mengartikan adanya hubungan saling cocok dan tidak menyinggung satu sama lain sehingga menghasilkan hubungan persahabatan yang baik.

\section{Representasi Tindakan Bromance}

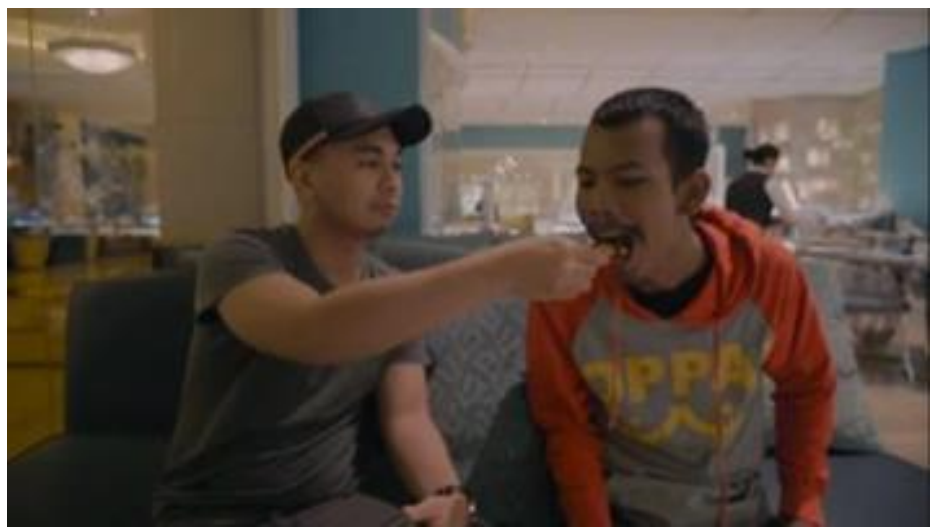

Gambar 5. Raditya Dika sedang menyuapakan makanan kepada Pandu Winoto

Pada scene 5 (06.36 - 07.16), terlihat Raditya Dika dan Pandu Winoto sedang berada di sebuah tempat makan besar dengan dekorasi yang dipenuhi lampu-lampu. Mereka duduk di satu sofa panjang dengan jarak posisi duduk tidak terlalu jauh, jaraknya kurang lebih hanya ada satu bantal pembatas.

Terkait dengan cara makan, Raditya Dika sebelumnya meme-ragakan dan mulai makan untuk dirinya sendiri. Selanjutnya, Raditya Dika meracikkan sajian dan langsung menyuapkan sajian tersebut ke Pandu Winoto. Dengan segera, Pandu Winoto membuka mulut dan menyambut makanan tersebut.
Pertemuan antara Raditya Dika dan Pandu Winoto dalam acara spesial tersebut juga dilakukan dengan bebe-rapa tindakan yang menggambarkan keintiman persahabatan bromance. Mulai dari posisi duduk dalam satu sofa yang tidak terlalu jauh antara satu dengan yang lain menggambarkan kedekatan hubungan persahabatan Raditya Dika dan Pandu Winoto.

Perlakuan yang menggambarkan suatu hubungan persahabatan antarsesama laki-laki terlihat romantis ditunjukan dengan jelas pada scene tersebut. Ketika Raditya Dika sedang menunjukan makanan asing bagi Pandu Winoto dan meracikan makanan tersebut lalu 
menyuapkan dengan senang hati. Ekspresi yang ditunjukkan oleh Raditya Dika terlihat tulus dan Pandu Winoto juga merasa nyaman karena mendapatkan perhatian dari sahabat akrabnya.

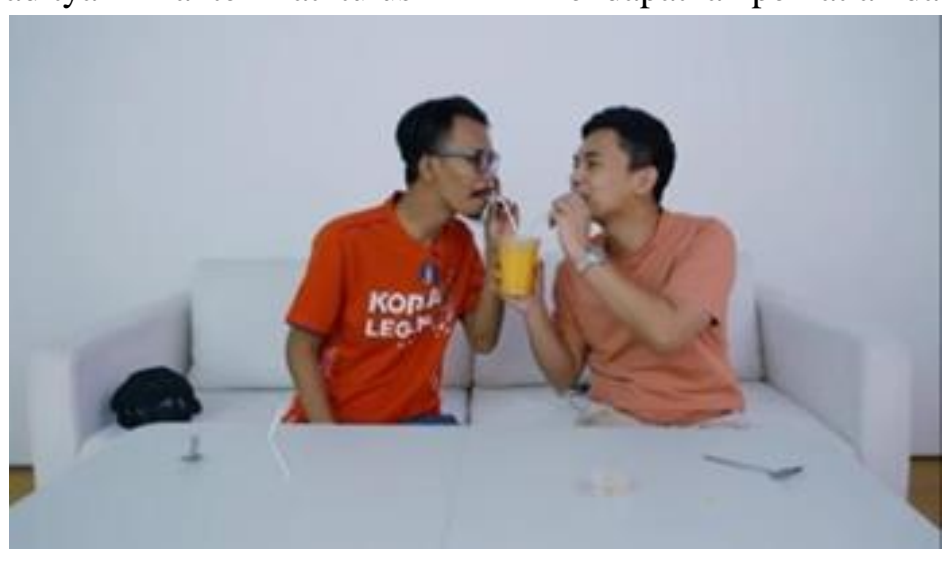

Gambar 6. Pandu Winoto dan Raditya Dika sedang minum dalam satu gelas yang sama

Scene 6 (09.47 - 10.00) menggunakan teknik pengambilan gambar medium shot karena menampilkan setengah badan dari Raditya Dika dan Pandu Winoto. Terlihat, berlatar di sebuah ruangan yang dengan menggunakan warna putih secara keseluruhan dan sofa panjang dengan dua ruas serta terdapat satu meja di depan mereka.

Pada minuman terakhir tersebut, Raditya Dika dan Pandu Winoto juga mencicipi secara bersamaan dalam satu gelas dengan dua sedotan. Terlihat Raditya Dika memegangi gelas tersebut dan memposisikan di tengahtengah mereka kemudian mulai mencicipi.
Pada scene tersebut, terlihat posisi Raditya Dika dan Pandu Winoto yang dekat dan saling berhadapan satu sama lain, menggambarkan seperti pasangan kekasih yang romantis. Ting- kat hubungan persahabatan antara Raditya Dika dan Pandu Winoto sudah mencapai keromantisan, yakni antar sesama laki-laki ketika melakukan tindakan seharihari. Hubungan tersebut juga hanya akan terjadi ketika kedua laki-laki memiliki banyak kecocokan dalam berbagai hal yang mendukung ikatan bromance semakin erat.

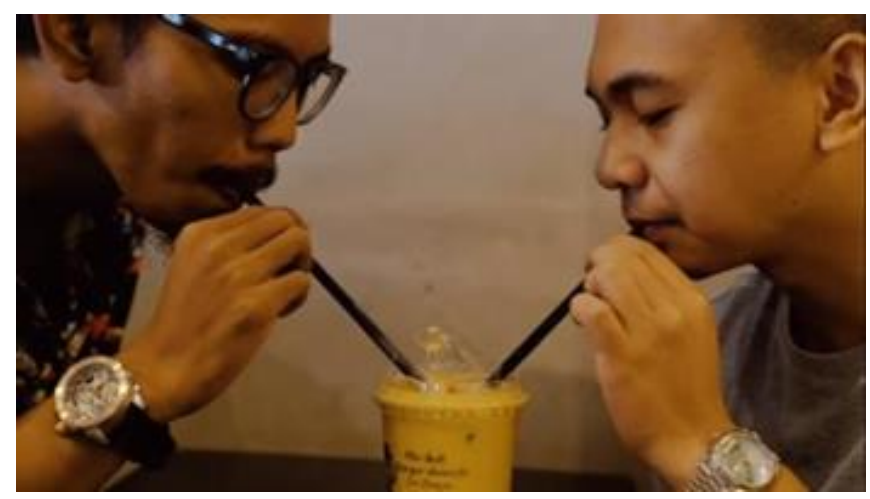

Gambar 7. Pandu Winoto dan Raditya Dika sedang minum dalam satu gelas yang sama

Pada scene 7 (09.51 - 10.08) terdapat pengambilan gambar yang berbeda dari sebelumnya yaitu dengan close-up. Raditya Dika dan Pandu Winoto terlihat dalam posisi saling berhadapan satu sama lain dengan satu meja berada di tengahnya. Namun, pengambilan tersebut hanya beberapa detik saja saat Raditya Dika dan Pandu Winoto mencicipi minuman. Ketika disajikan minuman untuk dicicipi dan selanjutnya dinilai, Raditya Dika 
dan Pandu Winoto kembali terlihat hanya mendapatkan satu gelas minuman saja.

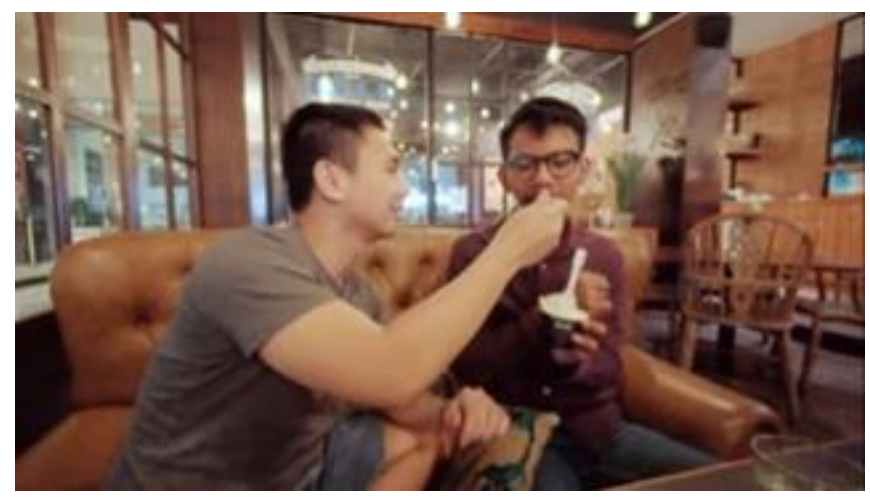

Gambar 8. Raditya Dika sedang menyuapakan es krim kepada Pandu Winoto

Pada scene 8 (13.45 - 13.57), teknik pengambilan gambar menggunakan medium shot dengan lensa yang lebar. Penggunaan lensa lebar terlihat pada jangkauan yang dihasilkan dengan jarak yang dekat sehingga menyebabkan terjadinya distorsi atau ketidaksesuaian dengan gambar nyata.

Scene 8 memerlihatkan Raditya Dika dan Pandu Winoto sedang duduk pada satu sofa panjang berwarna cokelat, dan latar tempat menggambarkan mereka sedang di sebuah tempat makan dan sudah disajikan makanan di meja. Makanan tersebut berupa es krim dan belum pernah dicicipi oleh Pandu Winoto sebelumnya. Hanya ada satu es krim dan dua di meja, dan ketika Raditya Dika menyuruh Pandu Winoto untuk mencicipi es krim tersebut.
Raditya Dika segera mengambil es krim tersebut dan langsung mengambilkan sesendok es krim untuk disuapkan ke Pandu Winoto.

Cuplikan yang memperlihatkan ketika Raditya Dika menyuapkan makanan berupa es krim kepada Pandu Winoto, dan es krim tersebut merupakan salah satu kesukaan Raditya Dika. Tindakan tersebut dapat diartikan sebegai bentuk keromantisan atau kasih sayang seperti yang dilakukan oleh sepasang kekasih. Namun ketika hal tersebut terjadi pada persahabatan antarlaki-laki menunjukan adanya hubungan yang erat dalam persababatan tersebut. Tindakan Raditya Dika dapat diartikan sebagai bentuk kasih sayang dan kepedulian kepada Pandu Winoto dapat merasakan kebahagian yang sama.

\section{Representasi Penampilan Bromance}

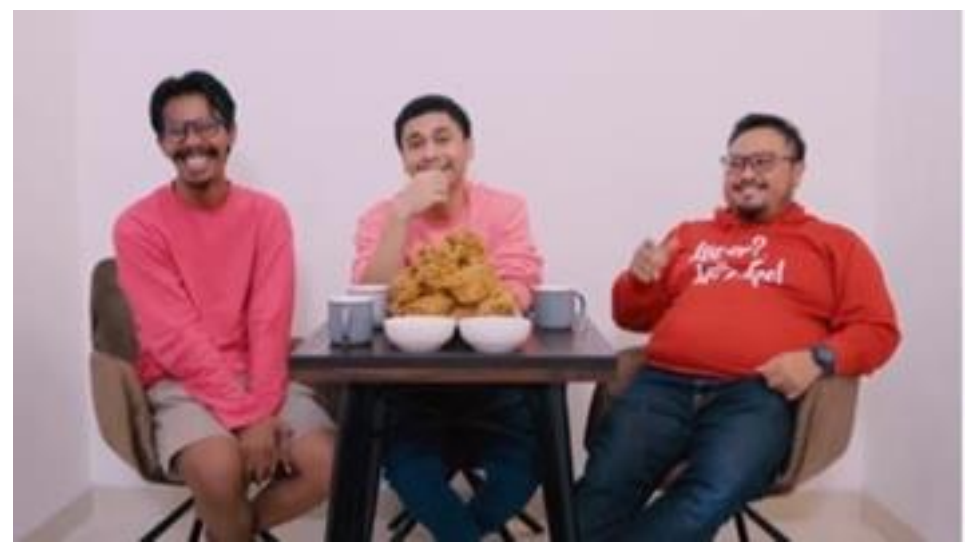

Gambar 9. Pandu Winoto, Raditya Dika, dan seorang pria sedang duduk 
Pada scene 9 (00.01 - 00.17) teknik yang digunakan dalam pengambilan gambar adalah medium shot karena hanya sebagian badan yang masuk dalam frame. Pada scene ini, terlihat tiga pria sedang duduk dimasingmasing kursi yang disediakan. Dengan beberapa alat makan di atas meja, yang akan digunakan mencicipi hidangan. Peneliti akan menganalisis lebih dalam terkait dengan penampilan Raditya Dika dan Pandu Winoto. Keduanya terlihat mengenakan pakaian dengan warna yang hampir sama. Gaya berpakaian juga diperlihatkan dengan dari model yang sama, yaitu sejenis jaket atau pakaian hangat.

Konten dengan tema hiburan selalu dibawakan oleh Raditya Dika ketika bersama Pandu Winoto karena memiliki hubungan persahabatan yang erat dan dapat dikategorikan sebagai bromance. Pada scene tersebut, secara keseluruhan, Raditya Dika mengajak Pandu Winoto untuk bersenang-senang dalam konten mencicipi makanan. Di sisi lain, penampilan antara Raditya Dika dan Pandu Winoto memiliki kesamaan, yaitu terkait dengan model dan warna pakaian yang hampir sama. Terlihat seperti pasangan yang menjalin asmara, seringkali menggunakan pakaian yang sama. Hal tersebut dapat menggambarkan kecocokan dari segi penampilan antara satu dengan yang lain. Sebagai contoh, pasangan laki-laki dengan perempuan menggunakan pakaian yang sama ketika sedang berada di tempat rekreasi. Hal tersebut menandakan bahwa mereka sedang menunjukan hubungan saling mencintai dan akan terlihat lebih romantis. Namun, memiliki makna yang berbeda ketika antarkedua lakilaki yang melakukan hal tersebut.

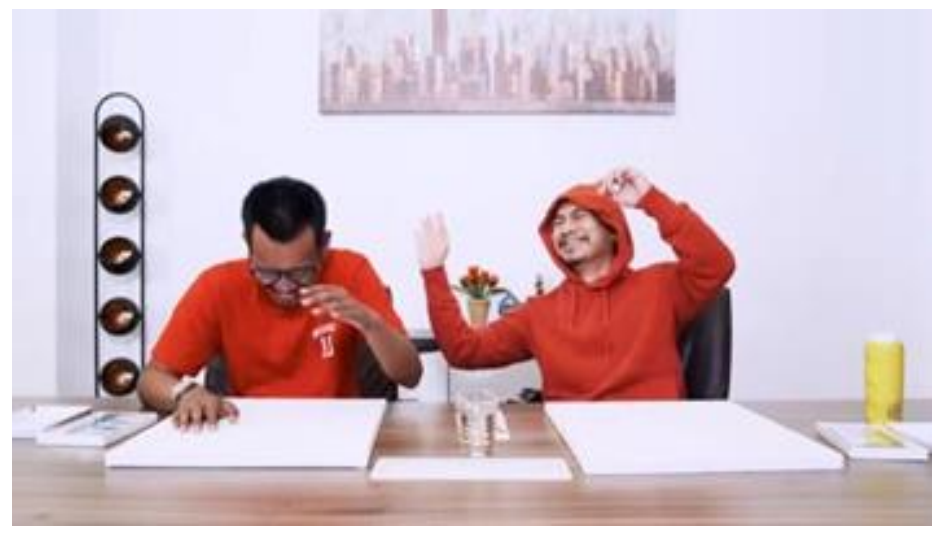

Gambar 10. Pandu Winoto dan Raditya Dika sedang bersiap untuk melukis

Scene $10 \quad(03.40 \quad-\quad 04.28)$, menggunakan teknik medium shot pada pengambilan gambar karena menampilkan setengah badan dari Raditya Dika dan Pandu Winoto, tetapi medium shot ini masih tetap meperlihatkan latar tempat sebagai frame, yakni di ruangan dengan satu lukisan besar di tengah dan terdapat dekorasi lain di bagian kiri atau belakang Pandu Winoto.

Pada scene ini, Raditya Dika dan Pandu Winoto sedang duduk berdua secara berdampingan. Posisi duduk antara Raditya Dika dan Pandu Winoto terlihat tidak terlalu jauh, dan masing-masing menggunakan bentuk dan model kursi yang sama. Raditya Dika dan Pandu Winoto juga terlihat mengenakan pakaian dengan warna yang sama namun berbeda jenis. Raditya Dika mengenakan pakaian hangat sedangkan Pandu Winoto kaos.

Penampilan atau cara berpakaian antara Raditya Dika dan Pandu Winoto sekilas menggunakan jaket atau kaos dengan warna yang sama. Hal tersebut menunjukan adanya kekompakan antara Raditya Dika dan Pandu Winoto. Pada salah satu pembahasan dalam scene tersebut, yang menunjukkan mereka 
sangat akrab adalah ketika Raditya Dika dan Pandu Winoto mengungkapan selalu bersamasama dalam melakukan berbagai hal menyenangkan. Raditya Dika juga sempat mengatakan apabila Alea (anak Radit) adalah anak Pandu Winoto juga, walaupun itu ditujukan untuk humor.

\section{Diskusi}

Menurut Hanani \& Reza (2019), terwujudnya hubungan yang akrab ditandai dengan tingkat keramah-tamahan dan kasih sayang yang tinggi, pengungkapan diri, rasa percaya serta tanggung jawab yang disampaikan melalui berbagai macam lambang tertentu.

Dalam menjalin hubungan dengan orang lain, individu harus mengetahui dan memahami bahwa setiap manusia adalah makhluk yang kompleks. Diibaratkan bawang, yang mana memiliki banyak lapisan dan ha-rus dikupas dalam setiap lapisan. Ketika dalam diri seseorang, terdapat berbagai hal yang berbeda terakit orang tersebut yang harus dipahami. Hal tersebut juga berlaku pada bromance di mana mereka saling berhubungan satu sama lain, dan akan berbagi lebih banyak mengenai diri masing-masing dan meningkatkan keakraban serta ketulisan atas hal yang mereka ketahui (Stefanie, 2016).

Terbentuknya persahabatan akrab diawali dengan beberapa faktor pendukung, seperti yang sudah dijelaskan sebelumnya. Beberapa faktor tersebut ketika sudah terbentuk menjadi persahabatan akrab akan menghasilkan manfaat dari suatu interaksi. Menurut A'yun (2018) hubungan persahabatan memiliki manfaat tersendiri, beberapa diantaranya ialah pertemanan, stimulasi kompetensi, dukungan fisik, dukungan ego, perbandingan sosial, dan intimasi.

Menjaga komunikasi menjadi cara paling penting dalam mem-pertahankan hubungan karena sebagai awal mula individu mengetahui dan meng-ungkapkan perasaan sayang kepada kekasih maupun teman dekat. Komunikasi secara baik menjadikan hubungan makin erat dan salah satu cara dalam menyelesaikan suatu permasalahan (Dewi \& Minza, 2016).

A'yuni (2015) mengartikan pemaafan sebagai kemungkinkan korban dalam membangun kembali kepercayaan dalam suatu hubungan dengan melakukan hal yang dapat dipercaya serta mendis-kusikan dengan terbuka mengenai kesalahan sehingga dapat melanjutkan hubungan yang baik antara korban dan pelaku.

Perkembangan hubungan juga mencakup adanya depenetrasi (penarikan diri) dan juga disolusi, yang mana manusia memiliki ketakutan terisolasi serta keengganan untuk memulai hubungan yang baru. Oleh karena itu, setiap individu memiliki kebebasan dalam menentukan pasa-ngan hidup baik untuk sahabat maupun kekasih (Stefanie, 2016).

Ketika persahabatan antarlaki-laki sudah terjalin dengan akrab, di dalamnya terdapat komunikasi antarteman sebaya, yakni proses pertukaran mengenai informasi antar individu secara verbal maupun non verbal yang dilakukan oleh hubungan pertemanan karena memiliki beberapa kesamaan (Sulistinganah, 2013).

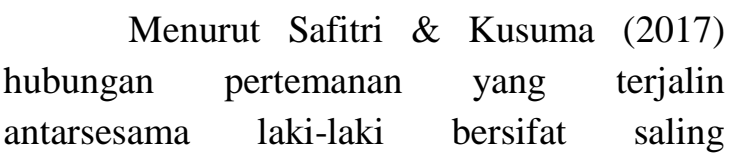
mendukung. Penelitian oleh Rahardjo (2015) mengungkapkan bahwa pandangan yang dimiliki oleh masyarakat umum mengenai maskulinitas pria yakni sosok yang mengutamakan penampilan otot kekar, gagah dan mandiri. Namun pada 1980 penggambaran sosok pria maskulin mulai berubah dengan berbagai tindakan yang dilakukan sehingga muncul sifat feminin yaitu mengurus anak, mengutamakan gaya hidup seperti mengikuti perkembangan jaman dari perwatan wajah hingga tren busana.

Konstruksi sosok pria yang sering dipakai untuk merepresentasikan gender atas ketangguhan ditunjukkan oleh sikap pantang menyerah dalam menyelesaikan tantangan. Dari sisi lain juga menunjukkan ketika pria memiliki jiwa tanggung, pantang menyerah dan 
bertanggung jawab (Haryanto, 2014). Febrieta (2016) menyebutkan bahwa laki-laki menyukai dukungan fisik yang muncul dari sahabatnya seperti menghabiskan waktu tertentu, melakukan aktivitas atau hobi secara bersamasama.

\section{KESIMPULAN}

Bromance merupakan konsep mengenai hubungan persahabatan antar lakilaki yang saling menyukai bahkan menyayangi satu sama lain, namun yang mereka lakukan tetap dalam batasan. Terkait dengan temuan penelitian yang telah dianalisis oleh peneliti menun-jukkan bahwa Raditya Dika dan Pandu Winoto memiliki hubungan sebagai sahabat akrab atau bromance. Repre-sentasi bromance antara kedua laki-laki yakni Raditya Dika dan Pandu Winoto pada video di channel YouTube Raditya Dika terbagi dalam tiga pengelompokan analisis yaitu dialog, tindakan, dan penampilan.

Representasi bromance dari segi dialog antara Raditya Dika dan Pandu Winoto, peneliti menemukan empat scene yang menunjukan kedekatan persahabatan mereka seperti Pandu Winoto meminta maaf kepada Raditya Dika karena telah melakukan kesalahan dengan mengatakan secara langsung, Raditya Dika mengatakan bahwa Pandu Winoto adalah pasangannya. Selanjutnya dari segi tindakan, peneliti menemukan empat scene yang merepresentasikan tindakan dalam pertemanan antara Ra-ditya Dika dan Pandu Winoto dapat dikategoriakan sebagai bromance seperti ketika Raditya Dika menyuapkan makanan kepada Pandu Winoto. Hal tersebut biasanya dilakukan oleh pasangan kekasih yang romantis namun pada scene tersebut menggambarkan sebagai keakraban pertemanan antar laki-laki dan tindakan tersebut peneliti mene-mukan dua scene yang serupa.

Scene lain yang dilihat dari segi tindakan, peneliti menemukan dua scene yang serupa yakni ketika dalam konten mencicipi minuman Raditya Dika dan Pandu Winoto minum dengan menggunakan sedotan pada satu gelas disaat yang sama. Hal tersebut menggambarkan pertemanan Raditya Dika dan Pandu Winoto memiliki ikatan yang erat layaknya pasangan yang sedang menjalin asmara. Terakhir representasi bro-mance dilihat dari segi penampilan, peneliti menemukan dua scene yang serupa yakni ketika Raditya Dika dan Pandu Winoto sedang membuat konten bersama mengenakan sejenis pakaian hangat dengan warna yang serupa. Hal tersebut meng-gambarkan kekompakan dalam persahabatan antara Raditya Dika dan Pandu Winoto. Penampilan dengan gaya tersebut biasanya dilakukan oleh sepasang kekasih karena sedang menunjukan bahwa mereka adalah pasangan yang intim. 


\section{DAFTAR PUSTAKA}

A'yun, Q. (2018). Hubungan kualitas persahabatan dengan forgiveness pada mahasiswa Fakultas Psikologi di Universitas Medan Area [Universitas Media Area]. http://repository.uma.ac.id/handle/1 23456789/9744

A'yuni, Q. Q. (2015). Literasi digital remaja di Kota Surabaya. Jurnal Fakultas Ilmu Sosial Dan Ilmu Politik Universitas Airlangga Surabaya, 4(2), 1-15. http://journal.unair.ac.id/literasidigital-remaja-di-kota-surabayaarticle-9195-media-136-category8.html

Clara Sari, A., Hartina, R., Awalia, R., Iriyanti, H., \& Zulkifli, N. (2018). Komunikasi dan media sosial. Research Gate.

DeAngelis, M. (2014). Reading the bromance: Homosocial relationships in film and television. In Wayne State University Press. Wayne State University Press. https://www.scribd.com/book/25185 8332/Reading-the-BromanceHomosocial-Relationships-in-Filmand-Television

Dewi, S. T., \& Minza, W. M. (2016). Strategi mempertahankan hubungan pertemanan lawan jenis pada dewasa muda. Gadjah Mada Journal of Psychology (GamaJoP), 2(3), 192205.

Febrieta, D. (2016). Relasi persahabatan. Jurnal Kajian Ilmiah UBJ, 16(2). https://doi.org/10.13140/RG.2.2.174 84.26248

Hanani, S. U., \& Reza, N. (2019). Represenasi bromance dalam film Indonesia berlatar belakang budaya jawa "Yowis Ben." Jurnal Kajian Komunikasi (METAKOM), 3(2), 5163. https://doi.org/10.23960/metakom. v3i2.65
Haryanto, I. (2014). "Kemunculan Diri dan Peran Pemilik Industri Media di Indonesia dalam Kerangka Teori Strukturasi Anthony Giddens.” ULTIMACOMM, 6(2), 58-71.

Noxinfluencer. (2020). Dasbor YouTube Stats \& Analytics.

Id.Noxinfluencer.Com. https://id.noxinfluencer.com/YouTu be/channel/UCorzsIrAxF4kCsALP6J 2EsA

Rahardjo, N. M. (2015). Representasi maskulinitas pria dalam iklan televisi (Analisis semiotika maskulinitas pria dalam iklan vaseline men face versi Ariel Noah ganteng maksimal). Universitas Katolik Widya Mandala.

Safitri, F., \& Kusuma, R. (2017). Keterbukaan diri gay kepada lakilaki heteroseksual mengenai orientasi seksual [Universitas Muhammadyah Surakarta]. http://eprints.ums.ac.id/54306/

Stefanie. (2016). Keterbukaan diri dalam membangun hubungan persahabatan diadik laki-laki dan perempuan. Jurnal UltimaComm, 8(2), 71-82.

Sulistinganah. (2013). Meningkatkan kemampuan komunikasi antar teman sebaya menggunakan bimbingan kelompok berbasis permainan pada siswa kelas $V$ di $S D$ negeri Parakancanggah kabupaten Banjarnegara tahun ajaran 2010/2013 [Universitas Negeri Semarang]. http://lib.unnes.ac.id/17876/

Utomo, R. T. (2017). Konstruksi media online nasional pada pemberitaan razia warung makan di Kota Serang (Analisis framing di Kompas. com dan Republika. co. id periode 11-16 Juni 2016) [University of Muhammadiyah Malang]. http://eprints.umm.ac.id/35196/

Vera, N. (2014). Semiotika dalam riset komunikasi. Ghalia Indonesia. 
Pandu Bagus Pratama \& Sumekar Tanjung 